\title{
Avaliação de Painéis Produzidos a partir de Resíduos Sólidos para Aplicação na Arquitetura
}

\author{
José C. Caraschi \\ Faculdade de Engenharia Industrial Madeireira, UNESP \\ Alcides L. Leão \\ Faculdade de Ciências Agronômicas, UNESP \\ Paula V. C. Chamma \\ Centro de Ciências Exatas e Sociais Aplicadas, USC
}

\begin{abstract}
Resumo: O presente trabalho tem por objetivo o reaproveitamento de resíduos sólidos na preparação de painéis para uso na arquitetura. Para atingir as metas propostas, painéis foram preparados a partir de resíduos provenientes de embalagens cartonadas e plásticas, utilizando-se como elemento de reforço, resíduos lignocelulósicos (casca de amendoim e de arroz). A concentração e a natureza dos resíduos utilizados como matriz e como carga foram variadas gerando doze condições experimentais diferentes. As propriedades avaliadas dos painéis foram o módulo de ruptura, módulo de elasticidade, tração perpendicular à superfície, inchamento em espessura, absorção de água e densidade. Todos os ensaios foram realizados segundo as normas ASTM D1037 e EN 317, referente à chapa de partículas. Os resultados foram analisados segundo a norma ANSI A208.1 que especifica as propriedades de desempenho requeridas para as chapas de partículas. Os painéis foram classificados como de baixa densidade, podendo ser utilizados como forros, divisórias, revestimento decorativos e demais aplicações que requerem as mesmas propriedades físicas e mecânicas. Os painéis a base de embalagem plástica reforçados com casca de arroz apresentaram propriedades superiores do que os demais painéis produzidos. O elemento arquitetônico desenvolvido neste estudo representa um novo mercado potencial, podendo ser empregado no ambiente urbano e rural, atendendo ao conceito de produto ecoeficiente.
\end{abstract}

Palavras-chave: Painéis, resíduos lignocelulósicos, embalagens plásticas, embalagens cartonadas, propriedades físicas e mecânicas.

\section{Evaluation of the Properties of Panels Produced from Solid Residues for Civil Construction}

Abstract: This work aims to evaluate the utilization of solid residues in the preparation of panels for civil construction. Panels were prepared from residues based on multilayer packages and plastics, reinforced with lignocellulosics residues (peanut shells and rice hulls). Several blends were prepared with different ratios of components, resulting in twelve treatments. The following physical and mechanical properties were evaluated: modulus of elasticity, modulus of rupture, perpendicular tension to panel plan, water swelling and absorption. All tests were carried out according to the ASTM D1037 and EN 317 standards concerning particleboard. The results were analyzed considering the ANSI A208.1 standard, which specifies the required properties for particleboards. The treatments using rice hulls as reinforcement load and plastic packaging as matrix presented better performance than the treatment using peanut shells. The panels tested were classified according to ANSI standards as low density panels. The present study shows that this technology is feasible and the results presented lead to a promising use as architectonical element.

Keywords: Panel, lignocellulosics residues, plastics packaging, carton packages, physical and mechanical properties.

\section{Introdução}

A tecnologia de produção de painéis ou chapas aglomeradas desenvolveu-se principalmente após a Segunda Guerra Mundial, em função da escassez da matéria-prima e, também, para a redução das perdas que ocorriam tanto na indústria madeireira como na exploração florestal. No Brasil, a produção de painéis de madeira aglomerada teve início em $1966^{[1]}$.
Os painéis estruturais são largamente utilizados na construção civil, principalmente nos Estados Unidos da América. No Brasil, os painéis mais produzidos são os de aglomerados segundo Juvenal e Mattos ${ }^{[2]}$. Esses painéis são geralmente produzidos a partir de partículas de madeira aglutinados com adesivos sintéticos ou outro aglomerante, sendo o conjunto prensado a quente por tempo suficiente para que a cura da resina se efetue. A princípio, esses pai-

Autor para correspondência: José C. Caraschi, Faculdade de Engenharia Industrial Madeireira, Universidade Estadual Paulista (UNESP),

CEP: 18409-010, Itapeva, SP, Brasil. E-mail: caraschi@itapeva.unesp.br 
néis podem também ser fabricados a partir de qualquer outro material lignocelulósico que lhes confiram alta resistência mecânica e peso específico pré-estabelecido, já que a composição química dos materiais lignocelulósicos é semelhante à da madeira, mais precisamente com a das madeiras duras que contêm menor teor de lignina e maior teor de hemiceluloses do tipo pentosanas ${ }^{[3]}$.

Quanto às propriedades e qualidade dos painéis, muitos são os fatores que contribuem para as características do produto final, no processo de produção de painéis. Porém, a obtenção de lâminas e produção de compensados de boa qualidade está estreitamente relacionada às características inerentes da madeira ou do material lignocelulósico utilizado, da resina e dos procedimentos empregados na confecção dos painéis ${ }^{[4]}$.

As indústrias de painéis aglomerados no Brasil, utilizam preferencialmente cavacos de madeira de reflorestamento provenientes de pinus e de algumas espécies de eucalipto ${ }^{[5-8]}$, o que determina, inclusive, uma melhor qualidade do produto, tendo em vista o melhor controle de homogeneidade da matéria-prima. Porém, os materiais lignocelulósicos proveniente de resíduos agroindustriais vêm sendo utilizados com sucesso na fabricação de chapas e painéis como, por exemplo, o bagaço de cana-de-açúcar na confecção de painéis aglomerados ${ }^{[9,10]}$ e fibras (epicarpo) de babaçu ${ }^{[1,12]}$. Segundo Lima ${ }^{[11,12]}$, painéis produzidos com $30 \%$ de fibras de babaçu apresentaram valores de módulo de ruptura (MOR) superiores aos valores mínimos exigidos pela norma comercial americana CS $236-66^{[13]}$ para painéis de densidade média. No mundo, $50 \%$ das indústrias desse produto empregam madeira de coníferas como matéria-prima principal, e outras empregam mais de uma espécie de madeira em suas linhas de produção. A multiplicidade de aplicações, principalmente na indústria moveleira, e mais recentemente, na construção civil, levou a geração de uma tecnologia avançada, com base na pesquisa de novos processos de utilização de novas matérias-primas.

O emprego de produtos à base de materiais lignocelulósicos (resíduos agroindustriais e fibras vegetais) na produção de chapas de aglomerados, chapas duras de fibra, chapas de média densidade e de compensados tem crescido ao longo do tempo e a tendência é de ter sua demanda aumentada devido ao aumento do seu preço e a diminuição da oferta de madeiras nativas comerciais e de madeira de reflorestamento. A madeira reconstituída, sob a forma de chapas e painéis compensados e laminados, tem adquirido importância e interesse cada vez maior ${ }^{[1]}$. Embora essa tendência favoreça a preservação de florestas nativas e o estímulo ao reflorestamento, esses não são exclusivamente os motivos para buscar materiais alternativos. A produção de painéis alternativos, com aproveitamento de resíduos de diferentes origens pode contribuir para o atendimento da demanda de painéis e estimular a produção de novos materiais e de painéis para uso arquitetônico ${ }^{[14]}$, adicionado ao fato de que o uso de resíduos lignocelulósicos e plásticos contribui para amenizar os impactos ambientais.
Pode ainda promover a adequada disposição final de resíduos e gerar materiais que preservem os recursos naturais.

A agroindústria brasileira apresenta inúmeros resíduos lignocelulósicos com potencialidades de aproveitamento na fabricação de novos materiais como, por exemplo, o bagaço de cana de açúcar ${ }^{[9]}$, palha e sabugo de milho ${ }^{[15]}$, juta ${ }^{[16]}$, algodão ${ }^{[17]}$, fibra de $\operatorname{coco}^{[18]}$, casca de $\operatorname{arroz}^{[19-22]}$, casca de amendoim ${ }^{[23,24]}$.

A casca de arroz é um resíduo gerado a partir processo de beneficiamento do arroz, no qual corresponde em peso, a $20 \%$ da produção de arroz ${ }^{[25]}$. A casca de arroz é composta quimicamente de $32 \%$ de celulose, $28 \%$ de lignina, $20 \%$ de hemiceluloses e $20 \%$ de matéria inorgânica. Segundo Souza e Yamamoto ${ }^{[25]}, 96 \%$ da matéria inorgânica é composto de sílica, óxido de potássio, sódio, magnésio e cálcio, e o restante são traços dos elementos ferro, manganês e alumínio.

Já a casca de amendoim, é um resíduo obtido do beneficiamento do amendoim, que é um produto agrícola de grande importância no Brasil devido à sua utilização na alimentação humana e animal, destacando-se a produção de grãos destinados à fabricação de doces e extração de óleo. O empenho no uso desses resíduos não é recente segundo Pablo et al. ${ }^{[23]}$ que desenvolveram estudos de painéis particulados, utilizando a casca de amendoim misturada com partículas de madeira.

As embalagens cartonadas ou multicamadas são utilizadas para envase de alimentos líquidos, encontradas em diferentes formatos. Elas são constituídas de seis camadas produzidas a partir de três materiais: papel duplex, alumínio e polietileno de baixa densidade (PEBD). A composição da embalagem cartonada é de $75 \%$ de papel duplex (fibra celulósica longa), $20 \%$ de PEBD e 5\% de alumínio em massa. As aparas de embalagens plásticas são compostas unicamente de PEBD.

Neste trabalho utilizou-se como elemento de reforço na confecção dos painéis, casca de arroz e de amendoim, ambos resíduos lignocelulósicos obtidos da agroindústria. Como matriz polimérica, utilizou-se as embalagens cartonadas pósconsumo, tipo de resíduo urbano, e aparas de embalagens plásticas de indústrias de alimentos, tipo de resíduo industrial, ambos em substituição as resinas de uréia-formaldeído e fenol-formaldeído, que são normalmente utilizadas pelas indústrias para produção de painéis destinados ao uso interno e externo ${ }^{[26,27]}$.

O objetivo do presente estudo foi produzir painéis à base de casca de amendoim e de casca de arroz como elemento de reforço, e de embalagens cartonadas e plásticas como matriz polimérica. É também objetivo avaliar os painéis quanto às suas propriedades físicas e mecânicas e evidenciar que os resíduos agroindustriais, industriais e urbanos podem e devem ser reaproveitados.

\section{Experimental}

Os resíduos agroindustriais empregados como elementos de reforço foram à casca de arroz (AR) coletada na Fazenda Experimental da UNESP, localizada no município de 
São Manuel-SP, e a casca de amendoim (AM), fornecida pela Indústria Amendoceres, localizada no município de São Paulo-SP. Como matriz polimérica, empregou-se dois tipos de materiais, as embalagens cartonadas pós-consumo (EC), um resíduo urbano também conhecido como embalagem longa vida e aparas de embalagens plásticas (EP), um resíduo industrial constituído basicamente de polietileno de baixa densidade (PEBD). As embalagens cartonadas, após coleta, foram abertas, lavadas com água e secas ao ar livre.

\section{Manufatura dos painéis}

Os painéis foram confeccionados utilizando-se diferentes proporções da matriz (EP ou EC) e do elemento de reforço (AR ou AM). As condições experimentais podem se visualizadas na Tabela 1. As combinações envolvendo os dois tipos de matriz e os dois tipos de reforço deram origem a doze experimentos apresentadas na Tabela 2.

As partículas dos resíduos de casca de amendoim e das embalagens cartonadas foram produzidas a partir da moagem deles em um moinho granulador horizontal, marca SEIBT. A casca de arroz não foi moída. A casca de arroz e a casca de amendoim moída foram secas em estufa com circulação de ar a uma temperatura de $105 \pm 3{ }^{\circ} \mathrm{C}$, até obter uma umidade média de aproximadamente $5 \%$. Todos os resíduos foram pesados separadamente e em seguida misturados e homogeneizados por agitação de acordo com as proporções estabelecidas na Tabela 2.

Após a mistura e homogeneização dos resíduos, estes foram distribuídos aleatoriamente dentro de um molde de madeira para a conformação inicial do colchão por meio de pressão manual exercida sobre a tampa do molde. Depois de formado o colchão, o molde de madeira foi retirado e o colchão pré-moldado foi levado à prensa.

Os painéis foram confeccionados em uma prensa hidráulica com fechamento simples e dois pratos com dimensões de $60 \mathrm{~cm} \times 60 \mathrm{~cm}$. Ao término da prensagem, o painel foi submetido a um carregamento por meio de uma chapa de ferro de $20 \mathrm{kgf}$ e com dimensões de $41 \mathrm{~cm} \times 41 \mathrm{~cm} \times 2 \mathrm{~cm}$, durante 15 minutos. A densidade nominal almejada para os painéis confeccionados foi de $0,90 \mathrm{~g} / \mathrm{cm}^{3}$. Os painéis foram produ-

Tabela 1. Delineamento experimental.

\begin{tabular}{|c|c|}
\hline Variáveis & Resíduos \\
\hline $\begin{array}{l}\text { Matriz (elemento matri- } \\
\text { cial) }\end{array}$ & $\begin{array}{l}\text { Embalagens plásticas (EP) } \\
\text { Embalagens cartonadas (EC) }\end{array}$ \\
\hline $\begin{array}{l}\text { Carga de reforço (elemento } \\
\text { estrutural) }\end{array}$ & $\begin{array}{l}\text { Casca de arroz (AR) } \\
\text { Casca de amendoim (AM) }\end{array}$ \\
\hline $\begin{array}{l}\text { Proporção matriz/reforço } \\
\text { com base no peso seco } \\
\text { total das partículas }(\%)\end{array}$ & $\begin{array}{l}40 \text { Matriz/60 Reforço } \\
50 \text { Matriz/50 Reforço } \\
60 \text { Matriz/40 Reforço }\end{array}$ \\
\hline Repetições & 3 \\
\hline Temperatura de prensagem & $150{ }^{\circ} \mathrm{C}$ \\
\hline Tempo de prensagem & 4 minutos \\
\hline Pressão de prensagem & $15,5 \mathrm{kgf} / \mathrm{cm}^{2}(1,520 \mathrm{MPa})$ \\
\hline
\end{tabular}

Tabela 2. Composição dos experimentos.

\begin{tabular}{|c|c|c|}
\hline n. & Experimentos & Composição \\
\hline 1 & EP40/AR60 & $\begin{array}{l}40 \% \text { de embalagens plásticas com } \\
60 \% \text { de casca de arroz }\end{array}$ \\
\hline 2 & EP50/AR50 & $\begin{array}{l}50 \% \text { de embalagens plásticas com } \\
50 \% \text { de casca de arroz }\end{array}$ \\
\hline 3 & EP60/AR40 & $\begin{array}{l}60 \% \text { de embalagens plásticas com } \\
40 \% \text { de casca de arroz }\end{array}$ \\
\hline 4 & EP40/AM60 & $\begin{array}{l}40 \% \text { de embalagens plásticas com } \\
60 \% \text { de casca de amendoim }\end{array}$ \\
\hline 5 & EP50/AM50 & $\begin{array}{l}50 \% \text { de embalagens plásticas com } \\
50 \% \text { de casca de amendoim }\end{array}$ \\
\hline 6 & EP60/AM40 & $\begin{array}{l}60 \% \text { de embalagens plásticas com } \\
40 \% \text { de casca de amendoim }\end{array}$ \\
\hline 7 & EC40/AR60 & $\begin{array}{l}40 \% \text { de embalagens cartonadas com } \\
60 \% \text { de casca de arroz }\end{array}$ \\
\hline 8 & EC50/AR50 & $\begin{array}{l}50 \% \text { de embalagens cartonadas com } \\
50 \% \text { de casca de arroz }\end{array}$ \\
\hline 9 & EC60/AR40 & $\begin{array}{l}60 \% \text { de embalagens cartonadas com } \\
40 \% \text { de casca de arroz }\end{array}$ \\
\hline 10 & EC40/AM60 & $\begin{array}{l}40 \% \text { de embalagens cartonadas com } \\
60 \% \text { de casca de amendoim }\end{array}$ \\
\hline 11 & EC50/AM50 & $\begin{array}{l}50 \% \text { de embalagens cartonadas com } \\
50 \% \text { de casca de amendoim }\end{array}$ \\
\hline 12 & EC40/AM60 & $\begin{array}{l}60 \% \text { de embalagens cartonadas com } \\
40 \% \text { de casca de amendoim }\end{array}$ \\
\hline
\end{tabular}

zidos com as seguintes dimensões: $35 \mathrm{~cm}$ de comprimento, $35 \mathrm{~cm}$ de largura e $1 \mathrm{~cm}$ de espessura.

\section{Ensaios físicos e mecânicos dos painéis}

Os painéis obtidos foram analisados segundo a norma ANSI A208.1 $1^{[27]}$ que especifica as propriedades necessárias para as chapas de partículas. As propriedades avaliadas foram o módulo de elasticidade (MOE), módulo de ruptura (MOR), tração perpendicular à superfície (TP), inchamento em espessura, absorção de água e densidade.

Nos ensaios mecânicos, para cada experimento, retiraram-se seis corpos-de-prova para o ensaio de flexão estática e seis para o ensaio de tração perpendicular à superfície. Os ensaios de flexão e tração perpendicular à superfície foram realizados de acordo com a norma ASTM D1037/96 $6^{[28]}$ e foram realizados em uma Máquina Universal de Ensaios EMIC, modelo DL-10.000 MF. Com base na referida norma, os corpos-de-prova para o ensaio de flexão foram confeccionados com 1,0 cm de espessura, 7,6 cm de largura e 29,0 cm de comprimento. Para o ensaio de tração perpendicular à superfície, definiu-se um corpo-de-prova quadrado de $5,00 \mathrm{~cm}$ de lado.

Para os ensaios físicos, foram retirados seis corposde-prova para cada experimento, com dimensões de $5,00 \mathrm{~cm} \times 5,00 \mathrm{~cm} \times 1,00 \mathrm{~cm}$ de comprimento, largura e espessura, respectivamente, de acordo com a norma EN 317/93 ${ }^{[29]}$. Esses corpos-de-prova foram submetidos aos seguintes ensaios físicos: densidade, teor de umidade, inchamento em espessura e absorção de água a 2 e 24 horas. 
Tabela 3. Classificação, valores mínimos e uso recomendado de painéis pela norma ANSI A208.1 (ANSI, 1993).

\begin{tabular}{ccccrcl}
\hline Classificação quanto a densidade & Categorias & Densidade $\left(\mathbf{g} / \mathbf{c m}^{3}\right)$ & MOR $(\mathbf{M P a})$ & MOE $(\mathbf{M P a})$ & $\mathbf{T P}(\mathbf{M P a})$ & Uso recomendado \\
\hline Baixa & LD1 & $<0,64$ & 3,00 & 550 & 0,10 & Enchimento de portas \\
Baixa & LD2 & $<0,64$ & 5,00 & 1025 & 0,15 & Enchimento de portas \\
Média & M1 & 0,64 a 0,80 & 11,00 & 1725 & 0,40 & Comercial \\
Média & MS & 0,64 a 0,80 & 12,50 & 1900 & 0,40 & Comercial \\
Média & M2 & 0,64 a 0,80 & 14,50 & 2250 & 0,45 & Industrial \\
Média & M3 & 0,64 a 0,80 & 16,50 & 2750 & 0,55 & Industrial \\
Alta & H1 & 0,80 & 16,50 & 2400 & 0,90 & Industrial \\
Alta & H2 & 0,80 & 20,50 & 2400 & 0,90 & Industrial \\
Alta & H3 & 0,80 & 23,50 & 2750 & 1,00 & Industrial \\
\hline
\end{tabular}

Para os ensaios de inchamento em espessura e absorção de água, os corpos-de-prova foram saturados em água destilada a $20{ }^{\circ} \mathrm{C}$, por 2 e 24 horas. Após esse período, os corpos-de-prova foram retirados da água e mantidos na posição vertical para secagem superficial e, na seqüência, foram pesados e medidos (em quatro pontos diferentes do corpode-prova) para a determinação do inchamento em espessura após 2 e 24 horas de submersão.

Para avaliar as propriedades físicas e mecânicas dos painéis, empregou-se como referência à norma ASTM D1037/96 ${ }^{128]} \mathrm{e}$ a norma EN $317 / 93^{[29]}$, utilizadas para chapas de partículas. Seus usos se justificaram pela semelhança do produto desenvolvido no presente estudo com uma chapa de partículas. Para enquadramento final dos painéis de cada experimento, utilizou-se a norma ANSI A208.1 $1^{[27]}$ simplificada na Tabela 3.

$\mathrm{Na}$ avaliação das propriedades físicas e mecânicas dos painéis, foi desenvolvida a análise de variância ANOVA, complementada pelo teste Tukey para comparação das médias.

\section{Resultados e Discussão}

Os resultados quanto às propriedades físicas e mecânicas dos painéis confeccionados são apresentados nas Tabelas 4 a 6 .

Na Tabela 4 são apresentados os valores médios de densidade e do teor de umidade dos painéis para cada experimento.
Os valores obtidos para densidade nos experimentos não diferenciaram significativamente, de acordo com o teste Tukey ao nível de $95 \%$ de probabilidade. Porém, os painéis confeccionados não obtiveram a densidade pré-determinada de $0,90 \mathrm{~g} / \mathrm{cm}^{3}$. Os valores médios de densidade obtidos foram de 0,66 a $0,79 \mathrm{~g} / \mathrm{cm}^{3}$, o que os classificam como painéis de média densidade, destinados ao uso comercial ou industrial, segundo a norma ANSI A208.1 $1^{[27]}$ e a NBR 14810-2 $2^{[30]}$. Com relação a Norma Comercial Americana CS 236-66 $6^{[13]}$, os painéis são classificados também como painéis de densidade média, do Tipo/Uso B. Esta classificação é importante, pois valores mínimos de módulo de elasticidade, módulo de ruptura, inchamento em espessura e absorção de umidade guardam estreita relação com a densidade.

Quanto ao teor de umidade, verifica-se que os painéis a base de casca de amendoim apresentaram valores superiores aos painéis a base de casca de arroz. Os painéis produzidos a base de embalagens cartonadas apresentaram teor de umidade superior aos painéis a base de embalagens plásticas. Este resultado pode ser atribuído ao fato das embalagens cartonadas serem compostas de $75 \%$ de papel duplex (fibra celulósica), ou seja, material este que absorve água devido aos grupos hidroxilas presente na celulose e hemiceluloses que são os principais componentes presentes no papel duplex.

Os ensaios de inchamento e absorção de água fornecem indicações a respeito das condições de adesão e de resistência das partículas que constituem o painel quando submeti-

Tabela 4. Valores médios de teor de umidade e de densidade.

\begin{tabular}{lccccc}
\hline $\mathbf{n .}$ & Experimentos & Teor de umidade (\%) & Desvio padrão & Densidade (g/cm $\left.\mathbf{c}^{\mathbf{3}}\right)$ & Desvio padrão \\
\hline 1 & EP40/AR60 & 5,85 & 3,76 & 0,69 & 0,11 \\
2 & EP50/AR50 & 3,79 & 0,73 & 0,71 & 0,07 \\
3 & EP60/AR40 & 3,39 & 0,44 & 0,74 & 0,04 \\
4 & EP40/AM60 & 7,16 & 4,14 & 0,67 & 0,09 \\
5 & EP50/AM50 & 5,36 & 0,85 & 0,73 & 0,09 \\
6 & EP60/AM40 & 5,58 & 4,53 & 0,67 & 0,09 \\
7 & EC40/AR60 & 6,95 & 2,07 & 0,71 & 0,17 \\
8 & EC50/AR50 & 7,67 & 4,69 & 0,75 & 0,09 \\
9 & EC60/AR40 & 7,81 & 3,69 & 0,73 & 0,07 \\
10 & EC40/AM60 & 11,66 & 3,68 & 0,66 & 0,03 \\
11 & EC50/AM50 & 9,07 & 3,48 & 0,68 & 0,09 \\
12 & EC40/AM60 & 9,12 & 2,76 & 0,76 & 0,03 \\
\hline
\end{tabular}


Tabela 5. Valores médios de absorção de água.

\begin{tabular}{llrrrr}
\hline $\mathbf{n}$. & Experimentos & \multicolumn{4}{c}{ Absorção de água (\%) } \\
\cline { 3 - 6 } & & 2 horas & Desvio padrão & 24 horas & Desvio padrão \\
\hline 1 & EP40/AR60 & 45,45 & 26,71 & 62,16 & 31,62 \\
2 & EP50/AR50 & 24,33 & 13,88 & 42,10 & 20,59 \\
3 & EP60/AR40 & 16,16 & 7,48 & 31,59 & 9,30 \\
4 & EP40/AM60 & 70,29 & 15,63 & 73,13 & 15,98 \\
5 & EP50/AM50 & 40,51 & 12,22 & 50,36 & 10,18 \\
6 & EP60/AM40 & 40,09 & 23,71 & 46,61 & 20,23 \\
7 & EC40/AR60 & 85,51 & 21,84 & 105,00 & 19,85 \\
8 & EC50/AR50 & 73,73 & 16,21 & 102,26 & 10,85 \\
9 & EC60/AR40 & 62,55 & 7,58 & 84,81 & 128,09 \\
10 & EC40/AM60 & 111,07 & 40,69 & 114,32 & 12,90 \\
11 & EC50/AM50 & 106,08 & 34,26 & 100,95 & 30,32 \\
12 & EC40/AM60 & 88,70 & 8,91 & 13,07 \\
\hline
\end{tabular}

Tabela 6. Valores médios de inchamento em espessura.

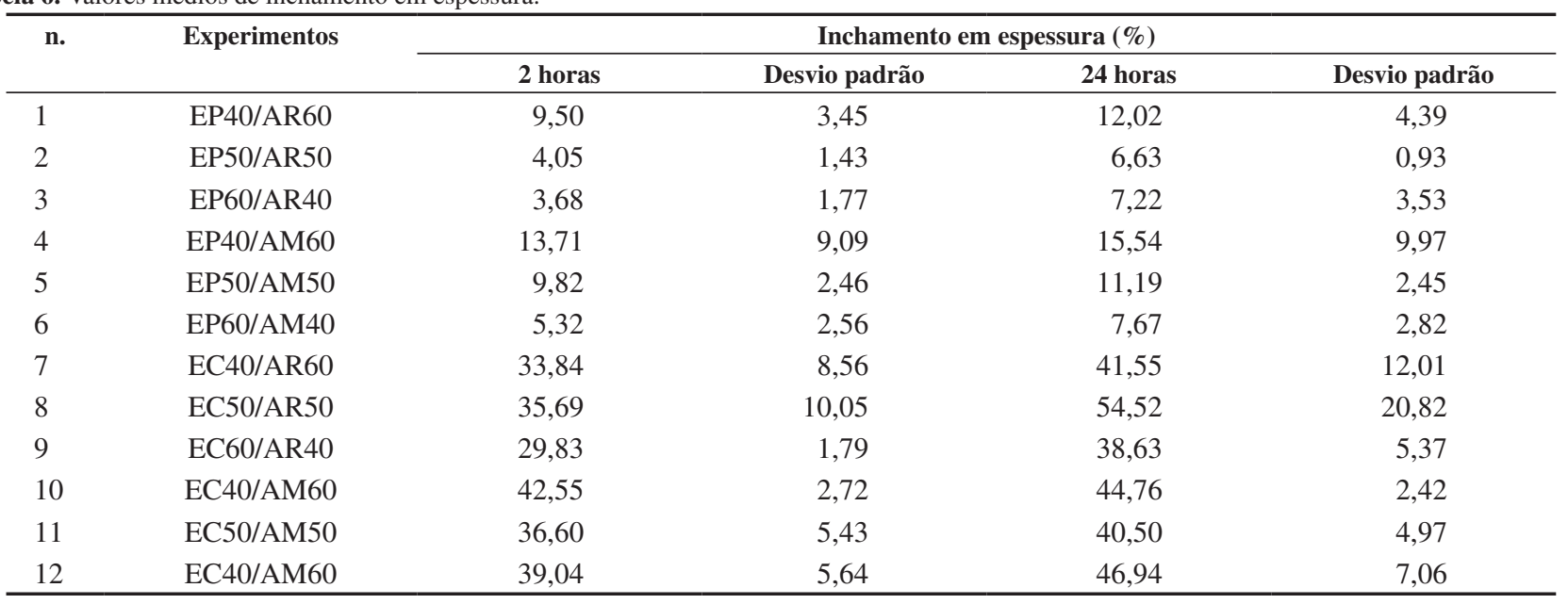

dos à imersão em água. Esses ensaios são realizados sistematicamente pelas indústrias, para controle de qualidade de seus produtos. Nas Tabelas 5 e 6 são mostrados os valores médios de absorção de água e de inchamento em espessura após 2 e 24 horas de imersão em água.

Com base nos resultados, verificou-se que os painéis a base de casca de amendoim apresentaram maior absorção de água e inchamento, valores estes acima dos valores estabelecido pela norma ANSI A208.1 $1^{[27]}$. A norma ANSI A208.1 especifica que o inchamento em espessura máximo permitido é de $8 \%$ para painéis de alta densidade. No presente estudo, somente os experimentos 2, 3 e 6 a base de embalagens plásticas apresentaram valores de inchamento após 24 horas de imersão em água próximos de $8 \%$ Esses experimentos, 2, 3 e 6, também não apresentaram diferença estatística com nível de significância de 5\%. Os valores de absorção de água dos painéis obtidos foram de 16,16 a 111,07\% após 2 horas e de 31,59 a 128,09\% após 24 horas de imersão em água. Quanto ao inchamento em espessura, os valores foram de 3,68 a 42,55\% após 2 horas e de 6,63 a 54,52\% após 24 horas. Observou-se diferença significativa na absorção e no inchamento em espessura, entre os painéis produzidos com dife- rentes tipos de elemento matricial (embalagens plásticas e cartonadas).

Segundo a norma comercial americana CS $236-66^{[13]}$ para painéis de densidade média de 0,60 a $0,80 \mathrm{~g} / \mathrm{cm}^{3}$ do tipo $1 \mathrm{~B}$ (painéis a base de uréia-formaldeído), nenhum dos experimentos a base de embalagem plástica ultrapassou a média máxima de inchamento em espessura recomendada pela norma.

Os resultados apresentados quanto ao inchamento em espessura e absorção de água permitem concluir que os painéis confeccionados com casca de arroz são melhores do que os produzidos com a casca de amendoim e com relação ao elemento matricial, painéis produzidos com embalagens plásticas apresentaram melhores resultados. Verificou-se também, que os experimentos que resultaram em maiores inchamento foram os mesmos que apresentaram maiores índices de absorção de água, resultados estes semelhantes aos encontrados por Cabral et al. ${ }^{[6]}$.

Os valores de inchamento em espessura (24 horas) obtidos neste trabalho para os painéis a base de embalagens plásticas com casca de arroz ou de amendoim foram inferiores em comparação com os apresentados por Iwakiri et al. ${ }^{[5]} \mathrm{e}$ 
Tabela 7. Valores médios de módulo de elasticidade (MOE), módulo de ruptura (MOR) e tração perpendicular à superfície (TP).

\begin{tabular}{llcccccc}
\hline $\mathbf{n .}$ & Experimentos & MOE $(\mathbf{M P a})$ & Desvio padrão & MOR (MPa) & Desvio padrão & TP (MPa) & Desvio padrão \\
\hline 1 & EP40/AR60 & 202,44 & 86,24 & 2,15 & 0,85 & 0,08 & 0,06 \\
2 & EP50/AR50 & 213,07 & 95,68 & 2,75 & 1,37 & 0,06 & 0,04 \\
3 & EP60/AR40 & 253,24 & 66,12 & 3,26 & 0,91 & 0,06 & 0,06 \\
4 & EP40/AM60 & 157,38 & 77,37 & 1,43 & 0,44 & 0,09 & 0,09 \\
5 & EP50/AM50 & 162,55 & 79,87 & 1,90 & 0,73 & 0,12 & 0,11 \\
6 & EP60/AM40 & 106,44 & 68,55 & 1,60 & 1,03 & 0,07 & 0,06 \\
7 & EC40/AR60 & 332,11 & 408,14 & 1,95 & 2,24 & 0,04 & 0,05 \\
8 & EC50/AR50 & 196,05 & 141,25 & 1,43 & 1,06 & 0,05 & 0,01 \\
9 & EC60/AR40 & 257,57 & 41,88 & 2,43 & 0,35 & 0,09 & 0,04 \\
10 & EC40/AM60 & 87,49 & 26,32 & 0,54 & 0,08 & 0,07 & 0,10 \\
11 & EC50/AM50 & 136,64 & 96,41 & 1,19 & 0,57 & 0,03 & 0,02 \\
12 & EC60/AM40 & 257,31 & 109,31 & 1,75 & 0,58 & 0,04 & 0,03 \\
\hline
\end{tabular}

Lima et al..$^{[12]}$, para painéis aglomerados de madeira Grevillea robusta com densidade de 0,58 a $0,77 \mathrm{~g} / \mathrm{cm}^{3}$ e de fibras de babaçu com densidade de $0,70 \mathrm{~g} / \mathrm{cm}^{3}$, respectivamente.

Ao julgar as propriedades físicas pela norma ANSI A208. $1^{[27]}$, os resultados dos painéis a base de embalagens cartonadas não foram satisfatórios com relação a absorção de água e ao inchamento em espessura, e isto se deve ao fato que as embalagens cartonadas são constituídas por $75 \%$ de papel duplex, um material hidrofílico.

Na Tabela 7, são apresentados os resultados quanto às propriedades mecânicas, no qual estão listados os valores médios de módulo de elasticidade, módulo de ruptura e tração perpendicular à superfície. Com base nos resultados, constata-se que houve nítida tendência de aumento do módulo de ruptura e do módulo de elasticidade dos painéis com o aumento da proporção do elemento matricial, apesar de que não foi constatada diferença significativa para o módulo de elasticidade e para a tração perpendicular à superfície.

Os valores de módulo de elasticidade e de ruptura obtidos nos experimentos não atingiram o mínimo recomendado pelos padrões e normas internacionais ANSI A208. ${ }^{[27]}$. Pela referida norma, apenas o painel de $50 \%$ de embalagem plástica com $50 \%$ de casca de amendoim, (EP50/AM50) atingiu o valor mínimo de tração perpendicular à superfície para painéis de baixa densidade categoria LD1 (Tabela 3). O melhor resultado obtido com relação ao módulo de ruptura foi o painel de $60 \%$ de embalagem plástica com 40\% de casca de arroz, (EP60/AR40).

Os resultados obtidos indicam que os painéis necessitaram de uma pressão de prensagem maior e uma proporção maior da matriz, garantindo uma maior estabilidade dimensional e melhor adesão entre as partículas e, por conseqüência, melhorando as propriedades mecânicas dos painéis.

Analisando a interferência das variáveis nos experimentos, notou-se que, na comparação dos experimentos utilizando casca de amendoim e casca de arroz, o emprego de casca de arroz levou a obtenção de painéis com propriedades superiores, com exceção daqueles resultados obtidos no ensaio de tração perpendicular à superfície e do módulo de ruptura, no qual não houve diferença significativa. Diante do exposto, comprovou- se que os experimentos constituídos por embalagem plástica reforçada com casca de arroz foram os melhores experimentos para a maioria das propriedades físicas e mecânicas avaliadas.

\section{Conclusões}

Dos painéis confeccionados, o que alcançou melhor resultado foi aquele composto por $60 \%$ de embalagem plástica com $40 \%$ de casca de arroz. Esse painel apresenta resultado que atendem à norma ANSI A208.1, em relação à densidade, inchamento e tração perpendicular à superfície, mas não atendem ao requisito módulo de ruptura e de elasticidade, sendo então preciso acrescentar um aditivo para melhorar a adesão entre o reforço e a matriz polimérica ou um tratamento das partículas.

Os painéis a base de embalagem cartonada apresentaram resultados insatisfatórios, principalmente com relação à absorção de água e ao inchamento em espessura.

Com relação à carga de reforço (elemento estrutural), verificou-se que a casca de arroz produziu painéis com propriedades superiores aos produzidos com casca de amendoim.

Os resultados obtidos classificam os painéis como de baixa densidade, podendo ser utilizados como forros, divisórias, revestimento decorativos e demais aplicações que requerem as mesmas propriedades físicas e mecânicas.

As embalagens cartonadas e plásticas pós-consumo podem ser também fontes de matéria-prima para a produção de materiais alternativos na arquitetura. $\mathrm{O}$ elemento arquitetônico desenvolvido nesse estudo atende ao conceito de produto ecoeficiente por ser produzido a partir de resíduos e por possibilitar seu uso no ambiente urbano ou rural.

\section{Referências Bibliográficas}

1. Mendes, L. M.; Albuquerque, C. E. C. \& Iwakiri, S. Revista da Madeira Wood Magazine, Edição Especial "Painéis", p.12 (2003).

2. Juvenal, T. L. \& Mattos, R. L. G. - Revista da Madeira Wood Magazine, Edição Especial "Painéis", p.24 (2003). 
3. Rowell, R. M.; Han, J. S. \& Rowell, J. S. - "Characterization and Factors Affecting Fiber Properties", in: Natural Polymers and Agrofibers Based Composites, Section II - Agrofibers Composites, p.115, Elisabete Frollini et al. (ed.). Embrapa Instrumentação Agropecuária Ed., São Carlos-SP (2000).

4. Marra, A. A. - "Technology of wood bonding: principle in practice". Van Nostrand Reinhold, New York (1992).

5. Iwakiri, S.; Shimizu, J.; Silva, J C.; Menessi, C. H. S. D.; Puehringher, A.; Venson, I. \& Larroca, C. - Revista Árvore, 28, p.883 (2004).

6. Cabral, C. P.; Vital, B. R.; Lucia, R. M. D. \& Pimenta, A. S. - Revista Árvore, 31, p.897 (2007).

7. Bortoletto Jr, G. - Scientia Forestalis, 63, p.65 (2003).

8. Hillig, E. - "Qualidade de chapas aglomeradas estruturais, fabricadas com madeiras de Pinus, Eucalipto e Acácia negra, puras ou misturadas, coladas com tanino-formaldeido". Dissertação de Mestrado, Universidade Federal de Santa Maria, Brasil (2000).

9. Okino, E. Y. A.; Andahur, J. P. V.; Santana, M. A. E. \& Souza, M. R. - Scientia Forestalis, 52, p.35 (1997).

10. Valdes, J. L.; Rodriguez, M. E. \& Sosa, P. - Revista ICIDCA Sobre los Derivados de la Cana de Azucar, 25, p.22 (1991).

11. Lima, A. M.; Lima, R. M.; Vidaurre, G. B. \& Brito, E. O. - "Avaliação da fibra de babaçu como matéria-prima para a fabricação de chapas de partículas", in: Anais do IX Encontro Brasileiro em Madeiras e Estruturas de Madeira, Arquivos\Trabalhos PDF\06-EB-21.pdf, Cuiabá-MT, (2004).

12. Lima, A. M.; Vidaurre, G. B.; Lima, R. M. \& Brito, E. O. - Revista Árvore, 30, p.645 (2006).

13. Commercial Standard - "Mat formed wood particleboard"; CS 236-66. (1968).

14. Chamma, P. V. C. - "Produção de Painéis a Partir de Resíduos Sólidos Para Uso Como Elemento Arquitetônico", Tese de Doutorado, Universidade Estadual Paulista, Brasil (2004).

15. Sampathrajan, A.; Vijayaraghavan, N. C. \& Swaminathan, K. R. - Bioresource Technology, 35, p.67 (1991).

16. Pandey, S. N.; Das, R. N. \& Day, A. - Research and Industry: a journal for entrepreneurs and technologics, 35, p.227 (1990).

17. Gurjar, R. M. - Bioresource Technology, 43, p.177 (1993).

18. Kaz, L.; d'Almeida, J. R. M., Barreto; D. W. \& Calado, V. - "Effect of the Molding Pressure on the Flexural Mechanical Behavior of Coir-phenolic Composites"; in: Proceedings of $5^{\text {th }}$ International Symposium on Natural Polymers and Composites and $8^{\text {th }}$ Brazilian Symposium on the Chemistry of Lignins and other Wood Components, Arquivos $(T r a b a l h o s$ PDFlpaper015, Águas de São Pedro-SP, (2004).
19. Youngquist, J. A. et al. - "Literature review on use of nonwood plant fibers for building materials and panels", Forest Products Laboratory, Madison (1994).

20. Pauleski, D. T. - "Características de compósitos manufaturados com polietileno de alta densidade (PEAD) e diferentes proporções de casca de arroz e partículas de madeira". Dissertação de Mestrado, Universidade Federal de Santa Maria, Brasil (2005).

21. Caraschi, J. C.; Leão, A. L. \& Chamma, P. V. C. - "Avaliação das Propriedades de Painéis Produzidos a partir de Resíduos Sólidos"; in Anais do X Encontro Brasileiro em Madeiras e Estruturas de Madeira, Arquivos\Trabalhos PDFl06-EB-06-33.pdf, Águas de São Pedro-MT, (2006).

22. Della, V. P.; Kühn, I. \& Hotza, D. - Química Nova, 24, p.778 (2001).

23. Pablo, A. A.; Perez, E. B. \& Ella, A. B. - "Development of particleboard on a pilot-plant and semi-commercial scale using plantation and secondary wood species and agricultural fibrous waste materials". Forest Products Research and Industries Development Commission, University of the Philippines, Philippines, (1975).

24. Batalla, L. \& Marcovich, N. E. - "Medium Density Particleboards from Peanut Shell Flour", in: Proceedings of $5^{\text {th }}$ International Symposium on Natural Polymers and Composites and $8^{\text {th }}$ Brazilian Symp. on the Chemistry of Lignins and other Wood Components. Arquivos $(T r a-$ balhos PDFlpaper110. Águas de São Pedro-SP, (2004).

25. Souza, M. F. \& Yamamoto, J. - Cerâmica, 45, p.34 (1999).

26. Nascimento, M. F. - "CPH - Chapas de Partículas Homogêneas - Madeiras do Nordeste do Brasil", Tese de Doutorado, Universidade de São Paulo, Brasil (2003).

27. American National Standards Institute - "Mat-formed wood particleboard: Specification; National Particleboard Association; ANSI A208.1-1993", Gaithersburg (1993).

28. American Society For Testing And Materials - "Standard test methods for evaluating properties of wood-base fiber and particle panel materials; ASTM D1037-96", Philladelphia (1996).

29. European Committee For Standardization - "Particleboards and fiberboards-determination of internal adhesion; EN 319, Bruxelas (1993).

30. Associação Brasileira de Normas Técnicas - "Chapas de Madeira Aglomerada, Parte 2: Requisitos; NBR 14810-2", Rio de Janeiro (2002).

Enviado: $15 / 05 / 08$

Reenviado: $29 / 09 / 08$

Aceito: 07/10/08 